\title{
Determinants of Awareness about Road Accidents and Knowledge of Traffic Rules: Empirical Evidence from Khulna City in Bangladesh
}

\author{
Saddam Hossain', Elena Maggi ${ }^{1}$, Andrea Vezzulli' ${ }^{1}$, Kazi Tanvir Mahmud² \\ ${ }^{1}$ Department of Economics, University of Insubria, Varese, Italy \\ ${ }^{2}$ Department of Economics, Southeast University, Dhaka, Bangladesh \\ Email:sdhossain1990@gmail.com, elena.maggi@uninsubria.it, linkedin.com/in/maggi-elena-839b0026, \\ andrea.vezzulli@uninsubria.it; linkedin.com/in/andrea-vezzulli-7177395,aushim@gmail.com
}

How to cite this paper: Hossain, S., Maggi, E., Vezzulli, A., \& Mahmud, K. T. (2021). Determinants of Awareness about Road Accidents and Knowledge of Traffic Rules: Empirical Evidence from Khulna City in Bangladesh. Theoretical Economics Letters, 11, 1247-1272.

https://doi.org/10.4236/tel.2021.116079

Received: November 6, 2021

Accepted: December 26, 2021

Published: December 29, 2021

Copyright $\odot 2021$ by author(s) and Scientific Research Publishing Inc. This work is licensed under the Creative Commons Attribution International License (CC BY 4.0).

http://creativecommons.org/licenses/by/4.0/

\begin{abstract}
This paper explores the social, demographic, economic, and other relevant determinants of road accident victims' awareness and knowledge regarding traffic rules. Data were collected from 200 victims of road traffic accidents (RTAs) in Khulna City, Bangladesh, using face-to-face surveys and interviews. Using probit model estimation, seven factors were found to be statistically significant: gender, training experience, education, access to media, previous involvement in road accidents, residence in urban areas, and high-skilled jobs. The results show that victims with training experience, higher education, access to media, and previous road accident experiences are more aware of road accidents and have learned adequate traffic rules. Victims who live in rural areas or have low-skilled jobs are less likely to have knowledge of traffic rules than those who live in urban areas or those with high-skilled jobs. In addition, males are likely to be more aware of RTAs than females.
\end{abstract}

\section{Keywords}

Accidents, Probit, Bivariate, Awareness, Knowledge

\section{Introduction}

Over the last four decades, fatalities and injuries related to road traffic accidents (RTAs) have increased consistently (World Health Organization, 2018a). Consequently, RTAs have become one of the major challenges in all developing countries, particularly in the least developed ones (Anwaar et al., 2012). The 
consensus in the existing literature is that road accidents have a negative impact on society, due to the loss of human lives and the loss of wealth (Rubayat \& Sultana, 2013). RTAs are the eighth leading cause of death worldwide (Ameratunga et al., 2006), and are expected to be the fifth leading cause of death by 2030 (World Health Organization, 2013; Naghavi et al., 2015). In low- and middle-income countries (LMICs) in recent years, RTAs caused more than $90 \%$ of deaths and injuries, and losses of up to 5\% of GDP, compared to losses of 3\% of GDP in other countries globally (World Health Organization, 2015, 2018b).

Rapid economic growth, motorization, and urbanization are the leading causes of the increase in RTAs in LMICs (Staton et al., 2016; Peden et al., 2018; Islam \& Dinar, 2021). In addition, lack of awareness of drivers and the public about RTAs, as well as overpopulation, the low quality of roads, lack of driver training, over speeding, and increased alcohol consumption are causing more RTAs (Sarkar et al., 2011; Biswas, 2012; Puvanachandra et al., 2012; Osayomi, 2013; Kakkar et al., 2014; Rasool et al., 2015; Bougueroua \& Carnis, 2016; Raina et al., 2016; Singh et al., 2016; Mohamed \& Bromfield, 2017; Balasubramanian \& Sivasankaran, 2021; Tsala et al., 2021). Working-class people and commuters (who are required to often be in traffic), lower socio-economic group of society and are mostly between 18 to 45 years of age, are the main victims of RTAs (Mashreky et al., 2010; Khare et al., 2012; Lin et al., 2013; Rubayat \& Sultana, 2013; Zhang et al., 2013; Kamruzzaman et al., 2014; Kyu et al., 2016; Raina et al., 2016; Baset et al., 2017; Shrestha et al., 2017; Ahmad et al., 2018; Goswami et al., 2018; Abegaz \& Gebremedhin, 2019).

In line with this global trend, RTAs are also a major problem in Bangladesh. In fact, RTAs have become more common in Bangladesh than in other LMICs in South Asia. The country's lack of adequate resources to help deal with RTAs leads to massive amounts of social and economic losses in terms of fatalities and property damage. RTAs are one of the main causes of these losses (Ahsan et al., 2011; Banik et al., 2011). Despite the growing burden caused by RTAs in Bangladesh, road safety remains a neglected issue, and relatively little knowledge exists on the factors contributing to the high number of RTAs. A report published by The Daily Star monthly forum in 2012 stated that, on average, 60 to 150 deaths per 10,000 motor vehicles occurred per year in Bangladesh, and the majority of the fatalities occurred due to drivers and public unawareness (Ahsan, 2012), which had the highest fatality rates compared to other developing countries, such as India (25.3), Sri Lanka (16), Malaysia (5.5), Cambodia (7), and Lao People's Democratic Republic (8) (Anjuman et al., 2007; Kamruzzaman et al., 2014).

\section{Research Motivation}

According to a report by the Bangladesh University of Engineering and Technology (BUET), nearly 12,000 people died and 35,000 others were injured due to road accidents in Bangladesh in 2012 (Labib et al., 2019). The most recent report 
published by the World Health Organization (2018a) estimated that in 2016, 24,954 people were killed by RTAs in Bangladesh. Mortality and morbidity rates of RTAs were significantly higher for males, pedestrians, and vehicle passengers (Baset et al., 2017; Ahmad et al., 2018; Goswami et al., 2018; Martin et al., 2018). Therefore, to prevent RTAs and improve the safety of roads, the Government of Bangladesh, as well as private institutions, civil societies, communities, and other non-government organizations, have taken several initiatives over the last decade (Mahmud et al., 2013). The most common measures are road construction and maintenance, safety improvement of existing roads, road-safety user guidelines, an increase of police agents on roads, traffic legislation to decrease unlicensed transport, and increased traffic signs on the roads (Mahmud et al., 2011; Mahmud et al., 2013; Ahmed et al., 2014; King, 2018). Despite all these initiatives taken by the government and non-government organizations, the rate of RTAs did not decrease significantly in Bangladesh. Therefore, it can be assumed that the RTA problem will remain severe in the future if public awareness of RTAs is not improved in Bangladesh.

Many studies have explored the types, causes, and consequences of RTAs in Bangladesh (Anjuman et al., 2007; Jabbar et al., 2009; Banik et al., 2011; Rubayat \& Sultana, 2013; Kamruzzaman et al., 2014; Baset et al., 2017). However, few studies have been conducted on the public awareness of RTAs and people's knowledge of traffic rules, mainly due to data limitations (Baset et al., 2017). To the best of our knowledge, only one study, conducted by Islam et al. (2018), focused on identifying the fundamental determinants that were associated with the knowledge of traffic rules in Bangladesh. However, yet no empirical study is conducted on how people's awareness level can enhance regarding RTAs in Bangladesh. Hence, the current research particularly takes deep contemplation on what are the factors that enhance the awareness level of an individual regarding RTAs. We believe that the finding will make a significant impact on the reduction of RTAs. Furthermore, it is also worthwhile to note that our study is quite different from that of Islam et al. (2018) since we focus our analysis simultaneously on two interrelated aspects, namely (i) the awareness level of the victims of RTAs, and (ii) victims' knowledge level of traffic rules. There is no doubt that a reduction in road accidents does not solely depend on people knowing traffic rules but also on their awareness level. Therefore, it is necessary to focus on both aspects.

This study explores the relationship between unobserved factors regarding the awareness of RTAs and the knowledge of traffic rules by using a bivariate probit model. One crucial factor, the victim's previous experience with RTAs, is considered in our case, whereas it was ignored in the model by Islam et al. (2018). Since it is still unclear what factors drive public awareness of RTAs and increase public knowledge of traffic rules, this study assesses the effect of social, demographic, economic, and other determinants of public awareness of RTAs and knowledge of traffic rules. Our findings would be useful for policymakers and 
aid in developing effective policies to reduce the rate of RTAs in Bangladesh.

The remainder of this paper is organized as follows. Section 2 is the literature review, followed by the conceptual framework of this study in Section 3. Sections 4 and 5 describe the data and the methodological assumptions adopted in the analysis, with a brief description of the main determinants. Section 6 discusses the results. Finally, section 7 concludes the study with the policy implications and limitations of the paper.

\section{Literature Review}

Sociodemographic and economic empowerment-related training increases people's skills and awareness of various socio-economic aspects of life (Hilton et al., 2016; Mahmud et al., 2017; Kabir et al., 2018). Therefore, it also creates opportunities to increase the understanding of RTAs issues and the knowledge of traffic rules (Banik et al., 2011; Khare et al., 2012; Nadesan-Reddy \& Knight, 2013; Abegaz et al., 2014; Touahmia, 2018). According to Zimmerman et al. (2015) and others accessing road traffic training is a pressing need for people willing to increase their knowledge and awareness about road traffic rules and accidents (Chang \& Yeh, 2007; Chen, 2009; Ali \& Tayfour, 2012; Anarkooli et al., 2017; Shrestha et al., 2017; Potoglou et al., 2018). However, a literature review conducted by Lin and Kraus (2009) showed that drivers who receive training have no significant reduction in the risk of motorcycle crashes. They argued that age, gender, location of licensing, and other factors of a person also can significantly impact on RTAs even though that individual receives training. Furthermore, they also claimed that individuals who received training may have more confidence in their operating skills and drive with more risk-taking behaviors. Therefore, further research is required to understand how the training factor correlated with people's awareness level and how its impact on RTAs.

Education is an essential factor in knowledge acquisition. It is closely related to the living standard of a person and also acts as a catalyst for enhancing their analytical skills (Anderson et al., 2009; Mahmud et al., 2014; Hilton et al., 2016; Mahmud et al., 2017). In the context of RTAs, education facilitates the understanding of road traffic rules formally (Pebalo et al., 2012; Kumar \& Srinivasan, 2013; Lin et al., 2013; Staton et al., 2016; Najaf et al., 2017; Shrestha et al., 2017). Similarly, gender also remains one of the main determinants of awareness about road accidents. In most cases, males are killed or injured in road accidents at a higher percentage compared to females (Tulu et al., 2017; Martin et al., 2018; Abegaz \& Gebremedhin, 2019; Balasubramanian \& Sivasankaran, 2021). However, the influence of gender is still unclear. For example, Diaz (2002), Latremouille et al. (2004), Rosenbloom (2009), and Abegaz and Gebremedhin (2019) demonstrated that females were more careful than males while crossing the road. In contrast, Latremouille et al. (2004) and Rosenbloom et al. (2004) found that women were less concerned than men while crossing a busy and dangerous road. In Bangladesh, it is generally believed that women are less aware of road traffic 
rules and accidents than men because they do not travel frequently. Likewise, previous RTAs experience enhances people's awareness of traffic accidents and encourages them to learn more about traffic rules (Watts \& Quimby, 1979; Horswill \& McKenna, 2004).

Apart from the factors mentioned above, other important demographic and socio-economic factors, such as age, marital status, income, occupation, residence, and access to media also influence the awareness and knowledge of road traffic rules and accidents. All these factors help people acquire knowledge, build awareness, and create opportunities to develop different skills. Age is an essential factor related to the decision-making capacity and experience of a person. Undoubtedly, age significantly impacts the awareness of RTAs (Pebalo et al., 2012; Singh et al., 2016; Abegaz \& Gebremedhin, 2019). When an individual is relatively very young or very old, that person has the highest risk of falling into the RTAs "trap" (Tay, 2008; Wei, 2010; Dandona et al., 2011; Eustace \& Wei, 2010; Chiou et al., 2013; Shrestha et al., 2017). The main reason for this segment of people being victims is reckless driving, overspeeding, unawareness of road traffic rules, physical changes, and poor driving ability at night (Abegaz \& Gebremedhin, 2019; Ahmad et al., 2018; Arafa et al., 2019; Tsala et al., 2021). A married person is more concerned about traffic rules and accidents than an unmarried person (Pebalo et al., 2012). This is because married people drive more carefully than unmarried persons, as they generally have more at stake regarding their family and are more aware of the harmful consequences of reckless driving (Ipingbemi, 2008; Akalanka et al., 2012).

People's occupations and places of residence are also important factors to consider (Chen et al., 2016; Raina et al., 2016; Singh et al., 2016; Abegaz \& Gebremedhin, 2019). In Bangladesh, formal or high-skilled workers (professional/official jobs and businesses that require good skills or formal education) comparatively have a higher level of road safety knowledge and know more about rules and regulations than informal or low-skilled workers (farmers, laborers, and other jobholders who are less educated and do not have any particular skill) because the majority of them are illiterate and have inadequate training regarding RTAs. Researchers observed that, due to a lack of awareness and information accessibility, as well as infrequent travel to other locations, farmers or workers living in rural areas are less concerned about road traffic rules and accidents than people living and working in urban areas (Zajac \& Ivan, 2003; Ipingbemi, 2008; Mahmud et al., 2009).

Income is considered an essential factor in gaining more knowledge about traffic rules and road accidents (Anwaar et al., 2012; Abegaz \& Gebremedhin, 2019). People with lower economic status are more likely to be victims of road accidents than others (Jeepura \& Pirasath, 2012; Yongchaitrakul et al., 2012). A person with an adequate income can spend much more on driving safer vehicles and having access to information related to traffic rules and regulations, as compared to a person with a low income. Media can also play a pivotal role in 
building social and economic awareness of RTAs (Kabir et al. 2018). Some researchers reported that having access to media increased the likelihood of people acquiring knowledge about traffic rules and also helped them gain access to daily information about road accidents (Whittam et al., 2006; Iipinge \& Owusu-Afriyie, 2014; Bonnet et al., 2018). As a result, people with access to media can become quickly and adequately aware of issues related to road accidents.

\section{Conceptual Framework}

So far, we have found that previous studies have been conducted to examine the main factors affecting RTAs. However, no individual research or empirical evidence so far exists on "what are the key social, demographic, economic and other factors that impact people awareness level regarding RTAs?" and "how these factors can be developed for individuals to drop RTAs?”. Therefore, to add original empirical evidence regarding some of the issues discussed in the literature review, this study hypothesizes that the victims' awareness of RTAs and knowledge of traffic rules are significantly affected by their social, demographic, and economic characteristics together with other related factors. Such factors include age, gender, marital status, level of income, educational qualification, previous road accident experience, former training of traffic rules, occupation, residence, and media access.

Age is correlated with the experience of a person which can also influence the social behavior and economic decision-making capacity of a person (Mahmud \& Hilton, 2020). Therefore, it can be logically hypothesized that an aged person having more experience would be more aware of the RTA than a younger and inexperienced group of people. Training and education are two important factors that help a person in acquiring knowledge, raising awareness on social aspects, and enhancing skills (Hilton et al., 2016; Mahmud et al., 2017; Kabir et al, 2018; Mahmud \& Hilton, 2020). Unwontedly, a trained and educated person would be in a more advantageous position as compared to an untrained and less educated person in acquiring knowledge about the traffic rules and regulations and following these traffic rules. Undoubtedly, income is one of the most important economic factors that can influence both the social and economic behavior of a person. A person having better income would be more capable of taking several safety measures (e.g., using a life jacket; driving/travel manuals, better transport, etc.) during traveling and also acquiring knowledge about the RTA than a person with little income. The stylized fact is that mass media can play a pivotal role in building social awareness among the people (Kabir et al., 2018). A person who has better access to the information published on mass media (e.g., newspaper, television, etc.) will be more aware of the RTA than a person having no or little access to the information provided by the mass media. Finally, that if any member of a family becomes the victim of the road accident, it is more likely that the victim or other members of that victim's family would be more aware about the RTA as compared to a family which never had an ex- 
perience of a road accident. We refer to the conceptual framework shown in Figure 1, where we assume that:

$H_{1}$ : Social, demographic, and economic factors influence the victims' awareness of road accidents and knowledge of traffic rules.

$\mathrm{H}_{2}$ : General education, media exposure, and specific traffic rules training increase victims' awareness of road accidents and knowledge of traffic rules.

$\mathrm{H}_{3}$ : Victims' previous experience of RTAs increases their awareness of RTAs and knowledge of traffic rules.

\section{Data Collection and Methodology}

The present study uses primary data collected by Islam et al. (2018) between Jan and Feb 2017 on victims who were admitted after road accidents in the Orthopaedics, Neurosurgery, and general wards of Khulna Medical College Hospital, Satkhira Sadar Hospital, and several private clinics from the Khulna and Satkhira districts. Data were collected using a questionnaire with face-to-face interviews from the 200 respondents who were admitted to the hospitals. The questionnaire is structured in five sections: victims' social, demographic and economic profiles, injury information, data related to treatment and cost, the effect on family, and information related to knowledge and awareness of RTAs ${ }^{1}$. All the respondents were informed and ensured that the data collected would be used only for research purposes. The sample included only respondents with a recent RTA in Khulna Division (Islam et al., 2018).

In Bangladesh, the Police department is the key and only official source of

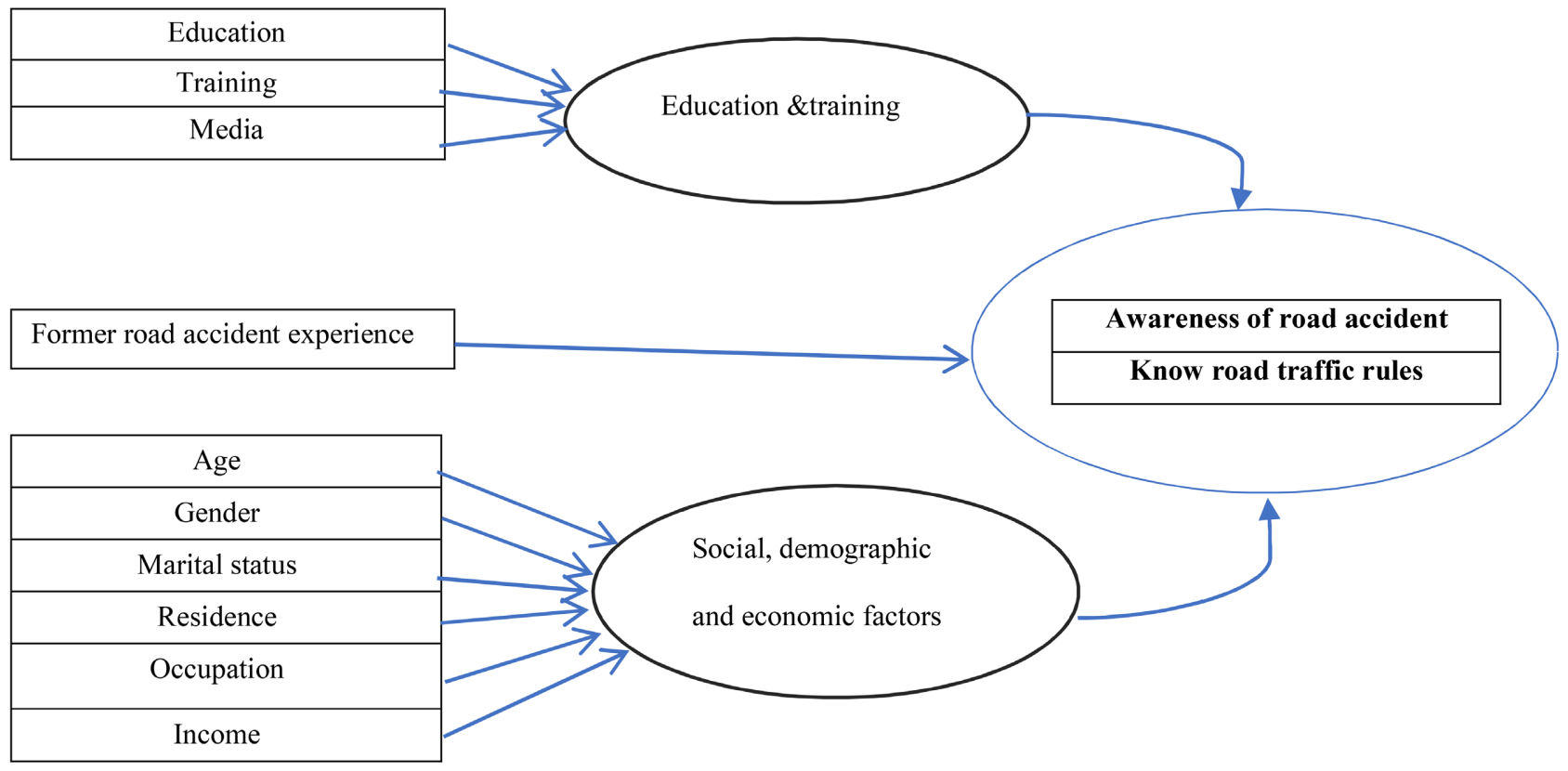

Figure 1. The conceptual framework of increasing victims' Awareness of RTAs and Knowledge of traffic rules.

${ }^{1}$ Questionnaire link:

https://f1000researchdata.s3.amazonaws.com/supplementary/15330/888bbad7-4ce4-4da8-922c-c4d3 8b419638.pdf. 
road accident data, as this department formally records and archives all the documents on the road accidents (Ishtiaque \& Ahmed, 2013; Ahmed et al., 2014). However, it is worth to be mentioned that the Police recorded only accidents that have been reported in the police station and, in the majority of cases, the information remains incomplete regarding victims and accidents characteristics (Baset et al., 2017). As such, the database suffers from a lack of necessary information. Therefore, without complete data, it is not possible to develop effective road safety interventions, because this problem created a bias in the results. However, the sample of 200 respondents used in this study, despite its limited size, represents an improved source of high-quality and complete data on the factors related to RTAs in Bangladesh, which helps to provide more reliable results for policymakers. Similar kinds of data sets have also been used in other studies conducted in the Maldives, Nepal, and Yemen for their research analysis (Waseela \& Laosee, 2015; Shrestha et al., 2017; Alfalahi et al., 2018). In this study, we used a probit model to assess the victim's overall knowledge of traffic rules and awareness levels of road accidents. Both binary logistic regression and probit models are widely accepted and commonly adopted when the dependent variable is dichotomous (Ai \& Norton, 2003; Hoetker, 2007). The model is developed and estimated by two separate, independent probit models to empirically investigate what social, demographic, and economic factors drive the victim to be aware of RTAs and increase their knowledge about traffic rules. Furthermore, as a robustness check, we also used a bivariate probit model. The first dependent variable $\left(y_{1}\right)$ is a dummy variable that is coded as "one" if the victims are aware of RTAs and "zero" otherwise. The second dependent variable $\left(y_{2}\right)$ is a dummy variable that is coded as "one" if the victims know about traffic rules and "zero" otherwise. The probit models can be written as:

$$
\begin{aligned}
& y_{1}=\beta X_{i}+\varepsilon \\
& y_{2}=\beta X_{i}+\varepsilon
\end{aligned}
$$

where the vector of independent variables $X$ includes: Age $=$ Age of the victims (Logarithm of years). Gender $=$ Gender of the victims (Dummy: male $=1$, female $=0$ ). Marital status $=$ Marital status of the victims (Dummy: Married $=1$, otherwise 0 ). Urban residence $=$ Residence of the victims (Dummy: urban $=1$, otherwise 0). Degree = Educational qualification of the victim's (Dummy: Degree $=1$, i.e., College degree or years of schooling is more than 12 , otherwise 0 ). Higher skilled job $=$ If the victim has high quality or regular job (profession/formal/official job that requires good skills or formal education) (Dummy: yes $=1$, otherwise 0 ). Lower skilled job $=$ If the victim has low quality or irregular job (farmers, laborers, and other jobs that do not require education or particular skills) (Dummy: yes $=1$, otherwise $=0$ ). Income $=$ monthly income of the victim's family (logarithm of income in Taka, the currency of Bangladesh). Previous experiences of RTAs $=$ Previous road accident experiences of the victim (Number). Previous training experience $=$ Whether the victim has experience in 
RTA-related training (dummy: yes $=1$, otherwise 0 ). Media exposure $=$ Whether the victim has access to media (dummy: yes $=1$, otherwise 0 ). $\beta=$ indicates the vector of coefficients to be estimated, and $\varepsilon=$ the equation's error term.

\section{Social, Demographic and Economic Status of the Respondents}

Descriptive statistics of the sample are shown in Table 1, which lists the variables used in the model to estimate the victim's awareness of RTAs and knowledge of traffic rules. The table shows the mean, standard deviation, minimum, and maximum of the variables from a total of 200 observations.

Out of the 200 respondents, 128 (64\%) claimed that they were aware of road accidents and 116 (58\%) knew traffic rules. Respondents aged 15 - 44 years were the group most affected by RTAs, representing $65 \%$ of the total number of respondents, and among the remaining victims, $7 \%$ were 0 - 14 years old and $28 \%$ were over 44 years old. The average age of the victims was 35 . The majority of victims were male (87\%), predominantly in the working-age, and $64 \%$ of victims were married. Generally, middle-aged people are more mobile than younger and aged people for their job and business activates. As a result, they are more likely to be victims of road accidents. In the majority of cases, married persons (especially male individuals) have to work more than other members in Bangladesh and are responsible for almost all economic and social activities (Uddin et al., 2017). As a result, these individuals may face family problems, including external challenges (quarreling with other family members, dealing with financial problems, and bearing social stress), which can increase their emotional stress and

Table 1. Descriptive statistics.

\begin{tabular}{cccccc}
\hline Variable & Obs & Mean & Std. Dev. & Min & Max \\
\hline Awareness of RTAs & 200 & 0.64 & 0.48 & 0.00 & 1.00 \\
Knowledge of traffic rules & 200 & 0.58 & 0.49 & 0.00 & 1.00 \\
Age & 200 & 3.44 & 0.49 & 1.95 & 4.25 \\
Income & 200 & 9.81 & 0.67 & 8.01 & 11.70 \\
Previous experiences of RTAs & 200 & 0.535 & 0.86 & 0.00 & 3.00 \\
Gender & 200 & 0.87 & 0.34 & 0.00 & 1.00 \\
Previous training experience & 200 & 0.665 & 0.47 & 0.00 & 1.00 \\
Lower skilled job & 200 & 0.32 & 0.48 & 0.00 & 1.00 \\
Higher skilled job & 200 & 0.47 & 0.50 & 0.00 & 1.00 \\
Media exposure & 200 & 0.385 & 0.49 & 0.00 & 1.00 \\
Marital status & 200 & 0.64 & 0.48 & 0.00 & 1.00 \\
Degree & 200 & 0.505 & 0.50 & 0.00 & 1.00 \\
Urban residence & 200 & 0.33 & 0.47 & 0.00 & 1.00 \\
\hline
\end{tabular}


lead to a lack of attention while driving, crossing, or walking on the street. Among all respondents, approximately $53.5 \%$ had at least one road traffic injury in the past. The highest proportion of accidents occurred among people living in rural areas. The respondents were most commonly high-skilled job holders or businessmen (47\%), followed by farmers and lower-level workers (32\%), and the remaining $21 \%$ were unemployed. More than half $(50.5 \%)$ of the victims had a degree. Finally, among the victims, $66.5 \%$ had previous training experiences regarding road traffic rules and regulations, and $38.5 \%$ had access to media.

\section{Result of the Probit Regression Analysis}

Two separate probit models were estimated to identify the factors that were significantly associated with the awareness of RTAs and knowledge of traffic rules. All analyses were conducted using STATA-64. The estimated results of the probit models are presented in Table 2. These results suggest that the individual's awareness of RTAs shows a positive and highly significant association with gen$\operatorname{der}(\beta=0.792, p<0.05)$, previous training experience $(\beta=0.933, p<0.01)$, access to media $(\beta=1.004, p<0.01)$, previous road accident experiences $(\beta=0.425$, $p<0.01)$, and having a degree $(\beta=0.826, p<0.01)$. The estimated marginal effects

Table 2. Results from maximum likelihood estimation of Probit models.

\begin{tabular}{ccc}
\hline $\begin{array}{c}\text { Dependent variables } \\
\text { Explanatory Variable }\end{array}$ & $\begin{array}{c}\text { Awareness of RTAs } \\
\text { Coefficient }\end{array}$ & $\begin{array}{c}\text { Knowledge of traffic rules } \\
\text { Coefficient }\end{array}$ \\
\hline Age & $-0.401[0.314]$ & $-0.566[0.357]$ \\
Income & $-0.279[0.205]$ & $-0.304[0.231]$ \\
Previous experiences of RTAs & $0.425[0.148]^{* * *}$ & $0.286[0.145]^{* *}$ \\
Male & $0.792[0.348]^{* *}$ & $0.549[0.466]$ \\
Previous training experience & $0.933[0.230]^{* * *}$ & $0.851[0.284]^{* * *}$ \\
Lower skilled job & $0.476[0.415]$ & $0.407[0.463]$ \\
Higher skilled job & $-0.098[0.353]$ & $1.087[0.431]^{* *}$ \\
Media exposure & $1.004[.0243]^{* * *}$ & $2.241[0.353]^{* * *}$ \\
Marital status & $0.215[0.316]$ & $-0.049[0.403]$ \\
Degree & $0.826[0.304]^{* * *}$ & $0.596[0.324]^{*}$ \\
Urban residence & $-0.002[0.232]$ & $0.486[0.275]^{*}$ \\
cons & $1.966[2.027]$ & $2.282[2.282]$ \\
Model parameters & 0.000 & 0.000 \\
LR chi2 $(11)$ & 0.248 & 0.456 \\
Prob $>$ chi2 & 64.88 & 124.07 \\
Pseudo R2 & & $5010 n t$ \\
\hline
\end{tabular}

Note: ${ }^{\star}=$ significant at the 10 percent level; ${ }^{* *}=$ significant at the 5 per cent level; ${ }^{\star *}=$ significant at the 1 per cent level. 
in Table 3 show that a male individual is $21.9 \%$ more likely to be aware of RTAs than females. Similarly, individuals who have training experience and access to media and higher education are $25.9 \%, 27.9 \%$, and $22.9 \%$, respectively more likely to be aware of RTAs than those with no training experience, no access to media, and no higher education. Furthermore, for each additional experience of a previous road accident, individual respondents are $11.8 \%$ more likely to be aware of the risk of RTAs than those who have no previous experience of a road accident.

Turning to the remaining control and other variables, low-skilled or irregular job holders $(\beta=0.476, p>0.10)$ and marital status $(\beta=0.215, p>0.10)$ exhibit a positive but insignificant association with the awareness of RTAs. Age $(\beta=$ $-0.401, p>0.10)$, income $(\beta=-0.279, p>0.10)$, high-skilled or regular jobs $(\beta=$ $-0.098, p>0.10)$, and living in the city $(\beta=-0.002, p>0.10)$ show a negative and insignificant association with awareness of RTAs. The results and the marginal effects of victims awareness of RTAs in this study are consistent with predicting $\mathrm{H}_{2}$ and $H_{3}$. However, this result is partially confirmed for $H_{1}$. Only gender remains consistent with $H_{1}$, and remaining variables such as low-skilled or irregular job holders, marital status, age, income, high-skill or regular job, and living in the city reject $H_{1}$. The results for knowledge of traffic rules are slightly different from those of the first model. Among the same independent variables used in the previous regression, the increase in victim's knowledge of traffic rules also shows a positive and significant association with having a previous training experience $(\beta=0.851, p<0.01)$, access to media $(\beta=2.241, p<0.01)$, previous road accident experiences $(\beta=0.286, p<0.05)$, and having a degree $(\beta$

Table 3. Marginal effect results of Awareness of RTAs and Knowledge of traffic rules.

\begin{tabular}{ccc}
\hline Explanatory Variable & $\begin{array}{c}\text { Awareness of RTAs } \\
\text { dy/dx }\end{array}$ & $\begin{array}{c}\text { Knowledge of traffic rules } \\
\text { dy/dx }\end{array}$ \\
\hline Age & $-0.111[0.086]$ & $-0.116[0.071]$ \\
Income & $-0.078[0.056]$ & $-0.062[0.046]$ \\
Previous experiences of RTAs & $0.118[0.038]^{* * *}$ & $0.059[0.028]^{* *}$ \\
Male & $0.219[0.093]^{\star *}$ & $0.112[0.094]$ \\
Previous training experience & $0.259[0.055]^{* * *}$ & $0.174[0.053]^{* * *}$ \\
Lower skilled job & $0.132[0.114]$ & $0.083[0.094]$ \\
Higher skilled job & $-0.027[0.097]$ & $0.222[0.083]^{* * *}$ \\
Media exposure & $0.279[0.059]^{* * *}$ & $0.459[0.044]^{* * *}$ \\
Marital status & $0.059[0.087]$ & $-0.010[0.082]$ \\
Degree & $0.229[0.080]^{* * *}$ & $0.122[0.064]^{*}$ \\
Urban residence & $-0.001[0.064]$ & $0.099[0.054]^{*}$ \\
\hline
\end{tabular}

Note: ${ }^{\star}=$ significant at the 10 percent level; ${ }^{\star *}=$ significant at the 5 per cent level; ${ }^{\star *}=$ significant at the 1 per cent level. 
$=0.596, p<0.10)$, with the exception of gender. Highly skilled workers $(\beta=$ 1.087, $p<0.05)$ and persons who live in cities $(\beta=0.486, p<0.10)$ also have a positive and significant correlation. Gender $(\beta=0.549, p>0.10)$ and low-skilled workers $(\beta=0.407, p>0.10$ ) have a positive but insignificant correlation with the victim's knowledge of traffic rules. Regarding age $(\beta=-0.566, p>0.10)$, income $(\beta=-0.304, p>0.10)$, and marital status $(\beta=-0.049, p>0.10)$, the results show a negative and insignificant association with the knowledge of traffic rules of the victims. The estimated marginal effects in Table 3 show that male respondents are $11.2 \%$ more likely to have knowledge of traffic rules than females. Finally, individuals who have training experience, access to media, a degree, high-skill jobs, and live in the city are 17.4\%, 45.9\%, 12.2\%, 22.2\%, and 9.9\% respectively more likely to have knowledge of traffic rules than those respondents who have, respectively, no training experience, no access to media, have no degree, have low-skilled jobs, and live in rural areas. Consequently, for each additional experience of a previous road accident, individuals are 5.9\% more likely to know traffic rules.

The results and the marginal effects of knowledge of traffic rules in this study are also consistent with predictions $H_{2}$ and $H_{3}$, while for $H_{1}$ the result is partially confirmed. Only high-skilled workers and persons who live in the city remain consistent with $H_{1}$ and remaining variables such as gender, marital status, age, income, and low-skilled or irregular job holders reject $H_{1}$. Taking into consideration the marginal effects of the variables, we noticed that victims with a degree, previous specific training on road traffic systems, and access to media have a comparatively higher chance of awareness of RTAs and knowledge of traffic rules.

In general, both models fit the data quite well, with an acceptable Pseudo R-square statistic of 0.248 (with an average chi-squared of 64.88 at the 0.001 significance level) and 0.456 (with an average chi-squared of 124.07 at the 0.001 significance level), with an overall accuracy of $78.5 \%$ and $80 \%$, respectively. Furthermore, we checked for possible high correlation problems among the variables, and in both models, there were no multicollinearity problems.

\subsection{Robustness Checks}

For the robustness check, we use a bivariate probit regression. This model can be generalized as:

$$
\begin{aligned}
& y_{1}^{*}=x_{1}^{\prime} \beta_{1}+\varepsilon_{1} \\
& y_{2}^{*}=x_{2}^{\prime} \beta_{2}+\varepsilon_{2}
\end{aligned}
$$

The model specifies the outcome as:

$$
\begin{aligned}
& y_{1}= \begin{cases}1 & \text { if } y_{1}^{*}>0 \\
0 & \text { if } y_{1}^{*} \leq 0\end{cases} \\
& y_{2}= \begin{cases}1 & \text { if } y_{2}^{*}>0 \\
0 & \text { if } y_{2}^{*} \leq 0\end{cases}
\end{aligned}
$$


where $y_{1}^{*}$ and $y_{2}^{*}$ represent the two dependent variables, $x_{1}^{\prime}$ and $x_{2}^{\prime}$ are the same set of independent variables used in the previous section, and $\varepsilon_{1}$ and $\varepsilon_{2}$ are the error terms in the model. The model is completed by assuming that the latent errors $\varepsilon_{1}$ and $\varepsilon_{2}$ have a bivariate standard normal joint distribution with correlation $\rho$. The bivariate probit model is a joint model for two binary outcomes when the two dependent variables are highly correlated. Table 4 reports the bivariate probit regression results, which show that the victim's awareness of RTAs and the victim's knowledge of traffic rules are relatively consistent with our Probit results. Finally, the ancillary parameter rho measures the correlation of the residuals from the two models. As it turns out, the two equations are strongly associated, having rho $=0.89$, which is significant (chi2 $(1)=$ 35.03 Prob $>$ chi $2=0.0000$ ) and indicates that the bivariate probit model has a significant correlation coefficient between the bivariate outcomes.

\subsection{Marginal Effects for the Bivariate Probit Model}

The estimated marginal effects from the bivariate probit model are shown in Table 5. pmarg1 and pmarg2 are the average marginal probabilities for awareness of RTAs and knowledge of traffic rules. The conditional marginal probabilities are pcond 1 , which represents the marginal probability of awareness of RTAs,

Table 4. Results from maximum likelihood estimation of bivariate Probit models.

\begin{tabular}{ccc}
\hline $\begin{array}{c}\text { Dependent variables } \\
\text { Explanatory Variable }\end{array}$ & $\begin{array}{c}\text { Awareness of RTAs } \\
\text { Coefficient }\end{array}$ & $\begin{array}{c}\text { Knowledge of traffic rules } \\
\text { Coefficient }\end{array}$ \\
\hline Age & $-0.439[0.314]$ & $-0.626[0.360]^{*}$ \\
Income & $-0.289[0.198]$ & $-0.324[0.216$ \\
Previous experiences of RTAs & $0.485[0.155]^{* * *}$ & $0.288[0.139]^{* *}$ \\
Gender & $0.832[0.347]^{* *}$ & $0.355[0.483]$ \\
Previous training experience & $0.951[0.232]^{* * *}$ & $0.689[0.269]^{* *}$ \\
Lower skilled job & $0.416[0.405]$ & $0.419[0.459]$ \\
Higher skilled job & $-0.193[0.355]$ & $1.061[0.412]^{* *}$ \\
Media exposure & $0.989[0.239]^{* * *}$ & $2.184[0.320]^{* * *}$ \\
Marital status & $0.293[0.319]$ & $0.1686[0.392]$ \\
Degree & $0.911[0.302]^{* * *}$ & $0.634[0.319]^{* *}$ \\
Urban residence & $-0.016[0.229]$ & $0.563[0.259]^{* *}$ \\
_cons & $2.101[1.966]$ & $2.780[2.25]$ \\
LR test of rho $=0$ : chi2 $(1)=35.03$ & & rho $=0.889$ \\
\hline athrho $=1.417^{* * *}$ & & Prob chi2 $=0.00$ \\
\hline
\end{tabular}

Note: ${ }^{\star}=$ significant at the 10 percent level; ${ }^{\star *}=$ significant at the 5 per cent level; ${ }^{\star \star \star}=$ significant at the 1 per cent level. 
Table 5. Marginal effects for the average and conditional probabilities of Awareness of RTAs and Knowledge of traffic rules.

\begin{tabular}{ccccc}
\hline & Pmarg1 & Pmarg2 & Pcond1 & Pcond2 \\
\hline Age & $-0.159[0.11]$ & $-0.225[0.13]^{*}$ & $-0.010[0.09]$ & $-0.095[0.09]$ \\
Income & $-0.105[0.07]$ & $-0.117[0.08]$ & $-0.023[0.06]$ & $-0.038[0.05]$ \\
$\begin{array}{c}\text { Previous RTAs } \\
\text { experiences }\end{array}$ & $0.175[0.06]^{* * *}$ & $0.104[0.05]^{* *}$ & $0.089[0.04]^{* *}$ & $-0.009[0.04]$ \\
Male & $0.301[0.13]^{* *}$ & $0.128[0.18]$ & $0.179[0.12]$ & $-0.054[0.13]$ \\
$\begin{array}{c}\text { Previous training } \\
\text { experience }\end{array}$ & $0.344[0.07]^{* * *}$ & $0.248[0.10]^{* *}$ & $0.150[0.08]^{* *}$ & $0.018[0.08]$ \\
Lower skilled job & $0.150[0.15]$ & $0.151[0.17]$ & $0.041[0.11]$ & $0.041[0.11]$ \\
Higher skilled job & $-0.069[0.13]$ & $0.381[0.15]^{* *}$ & $-0.263[0.11]^{* *}$ & $0.337[0.12]^{* * *}$ \\
Media exposure & $0.358[0.09]^{* * *}$ & $0.785[0.10]^{* * *}$ & $-0.128[0.10]$ & $0.435[0.11]^{* * *}$ \\
Marital status & $0.106[0.12]$ & $0.061[0.14]$ & $0.055[0.09]$ & $-0.007[0.10]$ \\
Degree & $0.329[0.11]^{* * *}$ & $0.228[0.12]^{* *}$ & $0.149[0.08]^{*}$ & $0.010[0.08]$ \\
Urban residence & $-0.005[0.08]$ & $0.202[0.10]^{* *}$ & $-0.113[0.06]^{*}$ & $0.163[0.08]^{* *}$ \\
\hline
\end{tabular}

Note: ${ }^{*}=$ significant at the 10 percent level; ${ }^{* *}=$ significant at the 5 per cent level; ${ }^{* *}=$ significant at the 1 per cent level.

giving the condition that individuals know traffic rules, and pcond2, which represents the marginal probability of knowledge of traffic rules, giving the condition that an individual is aware of RTAs.

According to the average marginal probabilities, a male is $30.1 \%$ more likely to be aware of RTAs than females. Individuals with previous training experience, individuals with access to media, and individuals with higher education were $34.4 \%, 35.8 \%$, and $32.9 \%$, respectively, more likely to be aware of RTAs than individuals with no training experience, no access to media, and higher education. For each additional experience of a previous road accident, individuals are 17.5\% more likely to be aware of RTAs. The average marginal effect of knowledge of traffic rules is slightly different from the average marginal effect of awareness of RTAs. Individuals with training experience, access to media, higher education, high-skilled jobs, and residence in urban areas are $24.8 \%, 78.5 \%, 22.8 \%, 38.1 \%$, and $20.2 \%$, respectively, are more likely to have knowledge of traffic rules than individuals with no training experience, no access to media, no higher education, low-skilled jobs, and residence in a rural area. For each additional experience of a previous road accident, an individual is $10.4 \%$ more likely to know traffic rules. Therefore, the average marginal effects from the bivariate probit model and standard probit models show robust similarities.

On the other hand, the marginal effect for conditional probabilities shows quite different and interesting results. The results from pcond 1 confirm that previous experiences of RTAs, previous training experience, and higher educa- 
tion increase the awareness of RTAs when the knowledge of traffic rules is already present. High-skilled jobs and residences in urban areas decrease awareness of RTAs when knowledge of traffic rules is already present. Media exposure and being a male have large marginal effects (pmarg1) on the individual's awareness level for RTAs. However, when considering the conditional probability (pcond1), these marginal effects become non-significant when the knowledge of traffic rules is already present. The results from pcond 2 show that previous experiences of RTAs, previous training experience, higher education, and being a male no longer significantly affect or increase traffic rules knowledge when individuals' awareness of RTAs is already present. High-skilled jobs, residence in urban areas, and access to media increase the knowledge of traffic rules even when individuals are already aware of the RTAs.

\subsection{Discussion}

The connections between social, demographic, and economic factors and RTAs have been the subject of a great deal of attention in recent years (Kayani et al., 2011; Kumar \& Srinivasan, 2013; Osayomi, 2013; Wiebe et al., 2016; Ahmad et al., 2018; Abegaz \& Gebremedhin, 2019). RTA exposure was significantly associated with economically productive and young-aged people (Martin et al., 2018). Previous studies have emphasized that this segment of the population tends to be more aggressive, with a higher tendency to violate traffic regulations while driving or riding and, therefore, to experience RTAs (Ipingbemi, 2008; Pebalo et al., 2012). In this study, we find that the most productive age groups most affected by RTAs are also those who are most active in the job market, and road accidents caused an apparent clear loss of productivity. Similar results were also found in prior studies conducted in Bangladesh and other developing countries such as Ghana, Egypt, Bhutan, Afghanistan, Zambia, Nepal, Tanzania, Kenya, Nigeria, Malaysia, Yemen, Pakistan, and more (Grimm \& Treibich, 2010; Mashreky et al., 2010; Karim et al., 2011; Bachani et al., 2012; Coleman, 2014; Biemba et al., 2015; Zimmerman et al., 2015; Adhikari, 2016; Huang et al., 2016; Karkee \& Lee, 2016; Saeed et al., 2016; Fouda et al., 2017; Alfalahi et al., 2018; Goswami et al., 2018; Wangdi et al., 2018).

In Bangladesh, inequality between males and females is extremely high in social and economic terms (Baset et al., 2017; Mahmud et al., 2019). The findings in this study highlighted that males are more conscious about RTAs than females. One of the main reasons is that females are usually in more subordinated social position than males because of society's patriarchal norms (Mahmud et al., 2019). In particular, rural women still have a lack of mobility, and their economic activities are often confined to household chores, while men have broader roles (Mahmud et al., 2014; Baset et al., 2017; Mahmud et al., 2019), and in most cases, men have the authority to take care of their family. For this reason, males travel more frequently than females and get more aware about RTAs. This result is consistent with the first hypothesis. Similar findings are also highlighted by 
Kumar and Srinivasan (2013), Tulu et al. (2017), and Abegaz and Gebremedhin (2019), who showed that men in Nepal and Ethiopia had more travel on the road because of their higher participation in work, business, or studies, while women were often restrained to their houses and were responsible for taking care of household chores.

As mentioned earlier, the impact of formal education on various aspects of people's daily lives can never be ignored (Mahmud et al., 2014; Hilton et al., 2016; Mahmud et al., 2017; Kabir et al., 2018). This study's empirical results are consistent with the second hypothesis. The results demonstrate that higher education had a positive link with the increase in knowledge of traffic rules and awareness of RTAs, which are critical factors for reducing RTAs. This result is also consistent with previous studies in the context of both developed and developing countries (Sharma, 2008; Mashreky et al., 2010; Akalanka et al., 2012; Jeepura \& Pirasath, 2012; Yongchaitrakul et al., 2012; Seid et al., 2015; Degais et al., 2018).

Previous training on traffic rules and the availability of media access also increases the chance of reducing RTAs by increasing awareness and knowledge of traffic rules (Abegaz et al., 2014). Undoubtedly, a trained person is more aware of risks and takes more judicious decisions (Hilton et al., 2016). Training helps novice drivers decrease their risk-taking attitude while driving as well as increases their understanding of the risks of dangerous behavior (McKenna et al., 2006; Nadesan-Reddy \& Knight, 2013). Similarly, media (radio, television, newspaper, internet services, etc.) encourages individuals to know about road traffic systems' rules and regulations and raises awareness about road accidents (Blantari et al., 2005; Salvarani et al., 2009). The present study also highlights this finding by showing that training experience and media access have a robust association with the awareness of road accidents and knowledge of traffic rules, consistent with the second hypothesis. A similar finding was also reported in a study on traffic accident prevention programs conducted in Brazil (Salvarani et al., 2009).

People's place of residence and employment status can also affect their level of awareness and knowledge of traffic rules. Raina et al. (2016) indicated that rural people were behind urban people in RTA knowledge. Consequently, it was reported that in Ethiopia and some other developing countries, more than two-thirds of all traffic accidents involved rural residents who were unskilled and unemployed or involved in informal economic activities (Zwerling et al., 2005; Jeepura \& Pirasath, 2012; Kumar \& Srinivasan, 2013; Shrestha et al., 2017; Abegaz \& Gebremedhin, 2019). The current study finds that people living in urban areas and people with a highly skilled job or business have a higher chance of knowing about traffic rules and regulations compared to people who live in villages or are unemployed. This result also confirms the hypothesis proposed in this study.

Moreover, involvement in a past road accident makes people more concerned 
about taking extra care of themselves during their travel. The current study shows that previous experience of road accidents has a positive association with a person's level of awareness of RTAs and knowledge of traffic rules, which confirms the third hypothesis. A previous study by Watts and Quimby (1979) also had similar findings indicating that there was a strong correlation between past accident experience and an increase in awareness level. They demonstrated that drivers with previous road accident records had fewer accident records afterward.

Finally, from the empirical results, it is worthwhile to mention that a high level of education increases the chance of a person being aware of RTAs and having knowledge of traffic rules. Moreover, the estimated effect of access to media and previous training programs on road traffic systems also increases the chance of being aware of RTAs and acquiring knowledge of traffic rules.

\section{Conclusion and Policy Implications}

Road accident-related injuries and fatalities are exceptionally high in Bangladesh and in other developing countries and disproportionally affect the economically productive segment of the population. However, by improving people's relevant social, demographic, and economic factors, the number of road accidents can be reduced. This paper shows that gender, road accident experience, availability of media connections, educational qualifications, job characteristics, place of residence, and past training about road traffic rules can improve an individual's awareness level of traffic accidents and knowledge of traffic rules. The Government of Bangladesh needs to increase the number of specific training courses on road traffic rules for all citizens and to encourage the media to increase the coverage of road traffic systems.

Therefore, necessary steps should be taken by policymakers to provide training to people about RTAs. It is essential to provide hands-on training, conducted by experienced trainers, for long durations. Training manuals about RTAs should be updated and provided to trainees at a low cost or for free. Necessary training allowances should be given so that people are encouraged to participate in future training programs. Essential steps should be taken to conduct mass media campaigns to build awareness of the prevalence and dangers of RTAs. Government and non-government organizations (NGOs) should provide the necessary support to produce high-quality public service announcements, documentaries, dramas, etc. on RTAs.

Governments or policymakers should take initiatives to include introductory courses related to road traffic systems in the education curriculum so that young people can easily gain knowledge regarding traffic rules and be aware of RTAs. Moreover, the government should focus on developing infrastructures that meet international quality standards by building effective partnerships among different stakeholders (government agencies, NGOs, and donor agencies).

The main contribution of this study is that these results provide new empirical 
evidence to support government and NGOs' policies to reduce RTA-related injuries and fatalities by strengthening factors that make people be aware of RTAs and increase their knowledge of traffic rules. Conversely, the following limitations should be considered while interpreting the findings of this study. First, this study considers only some specific public and private hospitals in Khulna city. Second, since the sample is limited to only 200 respondents involved in RTAs; hence, the findings may not be generalized to all road traffic victims. Further research is required to extend the data collection to all the hospitals in Khulna city and other cities in Bangladesh to increase the sample size and assess the external validity of these results.

\section{Acknowledgements}

The authors are grateful to Saiful Islam (Department of International Business, University of Dhaka) and Zeenat Akter for their exhaustive check and proofreading of this manuscript.

\section{Conflicts of Interest}

The authors declare no conflicts of interest regarding the publication of this paper.

\section{References}

Abegaz, T., \& Gebremedhin, S. (2019). Magnitude of Road Traffic Accident-Related Injuries and Fatalities in Ethiopia. PLoS ONE, 14, e0202240. https://doi.org/10.1371/journal.pone.0202240

Abegaz, T., Berhane, Y., Worku, A., \& Assrat, A. (2014). Effectiveness of an Improved Road Safety Policy in Ethiopia: An Interrupted Time Series Study. BMC Public Health, 14, Article No. 539. https://doi.org/10.1186/1471-2458-14-539

Adhikari, G. P. (2016). Road Traffic Accidents (RTAs) Trends on Kathmandu-Bhaktapur Road after Addition of Lanes. Open Journal of Civil Engineering, 6, 388-396. https://doi.org/10.4236/ojce.2016.63033

Ahmad, M., Rahman, F. N., Rahman, M. Z., \& Biswas, P. (2018). Road Traffic Injury among Pedestrians: An Emerging Research Focus in Bangladesh. KYAMC Journal, 9, 11-15. https://doi.org/10.3329/kyamcj.v9i1.36598

Ahmed, I., Ahmed, B., \& Hainin, M. R. (2014). Road Traffic Accident Characteristics in Dhaka, Bangladesh. Jurnal Teknologi, 71, 75-82. https://doi.org/10.11113/jt.v71.3763

Ahsan, H. M. (2012). Road Safety in Bangladesh: Key Issues and Countermeasures. Forum: A Monthly Publication of Daily Star, 6.

Ahsan, H. M., Raihan, M. A., Rahman, M. S., \& Arefin, N. H. (2011). Reporting and Recording of Road Traffic Accidents in Bangladesh. In 4th Annual Paper Meet and 1st Civil Engineering Congress (pp. 22-24). https://www.iebconferences.info

Ai, C., \& Norton, E. C. (2003). Interaction Terms in Logit and Probit Models. Economics Letters, 80, 123-129. https://doi.org/10.1016/S0165-1765(03)00032-6

Akalanka, E. C., Fujiwara, T., Desapriya, E., Peiris, D. C., \& Scime, G. (2012). Sociodemographic Factors Associated with Aggressive Driving Behaviors of 3-Wheeler Taxi Drivers in Sri Lanka. Asia Pacific Journal of Public Health, 24, 91-103. 
https://doi.org/10.1177/1010539510376304

Alfalahi, E., Assabri, A., \& Khader, Y. (2018). Pattern of Road Traffic Injuries in Yemen: A Hospital-Based Study. Pan African Medical Journal, 29, 1-9. https://doi.org/10.11604/pamj.2018.29.145.12974

Ali, G. A., \& Tayfour, A. (2012). Characteristics and Prediction of Traffic Accident Casualties in Sudan Using Statistical Modeling and Artificial Neural Networks. International Journal of Transportation Science and Technology, 1, 305-317. https://doi.org/10.1260/2046-0430.1.4.305

Ameratunga, S., Hijar, M., \& Norton, R. (2006). Road-Traffic Injuries: Confronting Disparities to Address a Global-Health Problem. The Lancet, 367, 1533-1540. https://doi.org/10.1016/S0140-6736(06)68654-6

Anarkooli, A. J., Hosseinpour, M., \& Kardar, A. (2017). Investigation of Factors Affecting the Injury Severity of Single-Vehicle Rollover Crashes: A Random-Effects Generalized Ordered Probit Model. Accident Analysis \& Prevention, 106, 399-410. https://doi.org/10.1016/j.aap.2017.07.008

Anderson, P., Chisholm, D., \& Fuhr, D. C. (2009). Effectiveness and Cost-Effectiveness of Policies and Programmes to Reduce the Harm Caused by Alcohol. The lancet, 373, 2234-2246. https://doi.org/10.1016/S0140-6736(09)60744-3

Anjuman, T., Hasanat-E-Rabbi, S., Siddiqui, C. K. A., \& Hoque, M. M. (2007). Road Traffic Accident: A Leading Cause of the Global Burden of Public Health Injuries and Fatalities. In Proceedings of the International Conference on Mechanical Engineering 2007 (pp. 29-31). Dhaka Bangladesh. https://me.buet.ac.bd/icme/icme2007/Proceedings/PDF/ICME07-AM-30.pdf

Anwaar, A., Anastasopoulos, P., Ong, G. P., Labi, S., \& Islam, M. B. (2012). Factors Affecting Highway Safety, Health Care Services, and Motorization-An Exploratory Empirical Analysis Using Aggregate Data. Journal of Transportation Safety \& Security, 4, 94-115. https://doi.org/10.1080/19439962.2011.619372

Arafa, A., El-Setouhy, M., \& Hirshon, J. M. (2019). Driving Behavior and Road Traffic Crashes among Professional and Nonprofessional Drivers in South Egypt. International Journal of Injury Control and Safety Promotion, 26, 372-378.

https://doi.org/10.1080/17457300.2019.1638419

Bachani, A. M., Koradia, P., Herbert, H. K., Mogere, S., Akungah, D., Nyamari, J., \& Stevens, K. A. (2012). Road Traffic Injuries in Kenya: The Health Burden and Risk Factors in Two Districts. Traffic Injury Prevention, 13, 24-30.

https://doi.org/10.1080/15389588.2011.633136

Balasubramanian, V., \& Sivasankaran, S. K. (2021). Analysis of Factors Associated with Exceeding Lawful Speed Traffic Violations in Indian Metropolitan City. Journal of Transportation Safety \& Security, 13, 206-222.

https://doi.org/10.1080/19439962.2019.1626962

Banik, B. K., Chowdhury, M. A. I., Hossain, E., \& Mojumdar, B. (2011). Road Accident and Safety Study in Sylhet Region of Bangladesh. Journal of Engineering Science and Technology, 6, 493-505.

Baset, U., Rahman, A., Alonge, O., Agrawal, P., Wadhwaniya, S., \& Rahman, F. (2017). Pattern of Road Traffic Injuries in Rural Bangladesh: Burden Estimates and Risk Factors. International Journal of Environmental Research and Public Health, 14, 1354. https://doi.org/10.3390/ijerph14111354

Biemba, G., Chanda-Kapata, P., Ngosa, W., Metitiri, M., \& Kanchele, C. C. (2015). Epidemiology and Factors Associated with Road Traffic Crashes in Zambia. Journal of 
Epidemiology and Preventive Medicine, 1, 108. https://doi.org/10.19104/jepm.2015.108

Biswas, S. K. (2012). Road Traffic Injuries: An Emerging Problem in Bangladesh. Faridpur Medical College Journal, 7, 5. https://doi.org/10.3329/fmcj.v7i1.10288

Blantari, J., Asiamah, G., Appiah, N., \& Mock, C. (2005). An Evaluation of the Effectiveness of Televised Road Safety Messages in Ghana. International Journal of Injury Control and Safety Promotion, 12, 23-29. https://doi.org/10.1080/17457300512331342199

Bonnet, E., Lechat, L., \& Ridde, V. (2018). What Interventions Are Required to Reduce Road Traffic Injuries in Africa? A Scoping Review of the Literature. PLoS ONE, 13, e0208195. https://doi.org/10.1371/journal.pone.0208195

Bougueroua, M., \& Carnis, L. (2016). Economic Development, Mobility and Traffic Accidents in Algeria. Accident Analysis \& Prevention, 92, 168-174.

https://doi.org/10.1016/j.aap.2016.03.016

Chang, H. L., \& Yeh, T. H. (2007). Motorcyclist Accident Involvement by Age, Gender, and Risky Behaviors in Taipei, Taiwan. Transportation Research Part F: Traffic Psychology and Behaviour, 10, 109-122. https://doi.org/10.1016/j.trf.2006.08.001

Chen, C. F. (2009). Personality, Safety Attitudes and Risky Driving Behaviors-Evidence from Young Taiwanese Motorcyclists. Accident Analysis \& Prevention, 41, 963-968. https://doi.org/10.1016/j.aap.2009.05.013

Chen, P. L., Jou, R. C., Saleh, W., \& Pai, C. W. (2016). Accidents Involving Pedestrians with Their Backs to Traffic or Facing Traffic: An Evaluation of Crash Characteristics and Injuries. Journal of Advanced Transportation, 50, 736-751.

https://doi.org/10.1002/atr.1372

Chiou, Y. C., Hwang, C. C., Chang, C. C., \& Fu, C. (2013). Modeling Two-Vehicle Crash Severity by a Bivariate Generalized Ordered Probit Approach. Accident Analysis \& Prevention, 51, 175-184. https://doi.org/10.1016/j.aap.2012.11.008

Coleman, A. (2014). Road Traffic Accidents in Ghana: A Public Health Concern, and a Call for Action in Ghana, (and the Sub-Region). Open Journal of Preventive Medicine, 4, 822-828. https://doi.org/10.4236/ojpm.2014.411092

Dandona, R., Kumar, G. A., Ameratunga, S., \& Dandona, L. (2011). Road Use Pattern and Risk Factors for Non-Fatal Road Traffic Injuries among Children in URBAN INDIA. Injury, 42, 97-103. https://doi.org/10.1016/j.injury.2009.10.048

Degais, W., Awooda, H. A., Elnimeiri, M. K. M., \& Kaddam, L. (2018). Epidemiological Pattern of Injuries Resulting from Road Traffic Accidents in Khartoum, Sudan. Health, 10, 816-822. https://doi.org/10.4236/health.2018.106061

Diaz, E. M. (2002). Theory of Planned Behavior and Pedestrians' Intentions to Violate Traffic Regulations. Transportation Research Part F: Traffic Psychology and Behaviour, 5, 169-175. https://doi.org/10.1016/S1369-8478(02)00015-3

Eustace, D., \& Wei, H. (2010). The Role of Driver Age and Gender in Motor Vehicle Fatal Crashes. Journal of Transportation Safety \& Security, 2, 28-44. https://doi.org/10.1080/19439961003590811

Fouda, E. Y., Youssef, M., Emile, S. H., Elfeki, H., Thabet, W., Abdallah, E., \& Khafagy, W. (2017). Pattern of Major Injuries after Motorcycle Accidents in Egypt: The Mansoura Emergency Hospital Experience. Trauma, 19, 39-45. https://doi.org/10.1177/1460408616652924

Goswami, U. K., Das, B. K., Dash, P. C., \& Islam, M. R. (2018). Demographic Characteristics and Etiology of Simple Mandibular Angle Fracture: Experience of 30 Cases in Dhaka City. Journal of Current and Advance Medical Research, 5, 45-48.

https://doi.org/10.3329/jcamr.v5i2.37058 
Grimm, M., \& Treibich, C. (2010). Socio-Economic Determinants of Road Traffic Accident Fatalities in Low- and Middle-Income Countries. ISS Working Paper Series/General Series, 504, 1-44.

Hilton, D., Mahmud, K. T., Shamsul Kabir, G. M., \& Parvez, A. (2016). Does Training Really Matter to the Rural Poor Borrowers in Bangladesh? A Case Study on BRAC. Journal of International Development, 28, 1092-1103. https://doi.org/10.1002/jid.3133

Hoetker, G. (2007). The Use of Logit and Probit Models in Strategic Management Research: Critical Issues. Strategic Management Journal, 28, 331-343. https://doi.org/10.1002/smj.582

Horswill, M. S., \& McKenna, F. P. (2004). Drivers' Hazard Perception Ability: Situation Awareness on the Road. In S. Banbury, \& S. Tremblay (Eds.), A Cognitive Approach to Situation Awareness (pp. 155-175). Ashgate.

Huang, L., Adhikary, K. P., Choulagai, B. P., Wang, N., Poudyal, A. K., \& Onta, S. R. (2016). Road Traffic Accident and Its Characteristics in Kathmandu Valley. Journal of the Nepal Medical Association, 55, 1-6. https://doi.org/10.31729/jnma.2829

Iipinge, S. M., \& Owusu-Afriyie, P. (2014). Assessment of the Effectiveness of Road Safety Programmes in Namibia: Learners' Perspective. Journal of Emerging Trends in Economics and Management Sciences, 5, 532-537.

Ipingbemi, O. (2008). Spatial Analysis and Socio-Economic Burden of Road Crashes in South-Western Nigeria. International Journal of Injury Control and Safety Promotion, 15, 99-108. https://doi.org/10.1080/17457300802150785

Ishtiaque, A., \& Ahmed, B. (2013). Urban Road Accidents in Dhaka, Bangladesh. In 16th International Conference on Road Safety on Four Continents. https://discovery.ucl.ac.uk/id/eprint/1418967

Islam, M. A., \& Dinar, Y. (2021). Evaluation and Spatial Analysis of Road Accidents in Bangladesh: An Emerging and Alarming Issue. Transportation in Developing Economies, 7, Article No. 10. https://doi.org/10.1007/s40890-021-00118-3

Islam, R., Khan, M. A., Nath, K. D., Hossain, M., Mustagir, G., \& Taneepanichskul, S. (2018). Determinants of Road Traffic Injury at Khulna Division in Bangladesh: A Cross Sectional Study of Road Traffic Incidents. F1000Research, 7, 1238. https://doi.org/10.12688/f1000research.15330.1

Jabbar, M. A., Islam, M. Z., Sultana, R., \& Akhter, S. F. U. (2009). Risk Factors of Road Traffic Accidents (RTA) in Context of Bangladesh. Journal of Dhaka Medical College, 18, 161-165. https://doi.org/10.3329/jdmc.v18i2.6279

Jeepura, P., \& Pirasath, S. (2012). Road Traffic Accidents in Eastern Sri Lanka: An Analysis of Admissions and Outcome. Sri Lanka Journal of Surgery, 29, 72-76. https://doi.org/10.4038/sljs.v29i2.3945

Kabir, G. M. S., Mahmud, K. T., Hassan, A., Hilton, D., \& Islam, S. M. (2018). The Role of Training in Building Awareness about Formalin Abuse: Evidence from Bangladesh. International Journal of Islamic and Middle Eastern Finance and Management, 11, 96-108. https://doi.org/10.1108/IMEFM-08-2017-0198

Kakkar, R., Aggarwal, P., Kakkar, M., Deshpande, K., \& Gupta, D. (2014). Road Traffic Accident: Retrospective Study. Indian Journal of Scientific Research, 5, 59-62.

Kamruzzaman, M., Haque, M., \& Washington, S. (2014). Analysis of Traffic Injury Severity in Dhaka, Bangladesh. Transportation Research Record: Journal of the Transportation Research Board, 2451, 121-130. https://doi.org/10.3141/2451-14

Karim, M., Khan, A. W., \& Farah, S. (2011). Economic Impact of Road Traffic Accident on Patients Attending at National Institute of Traumatology and Orthopedic Rehabili- 
tation (NITOR), Dhaka. Ibrahim Cardiac Medical Journal, 1, 45-49.

https://doi.org/10.3329/icmj.v1i2.13560

Karkee, R., \& Lee, A. H. (2016). Epidemiology of Road Traffic Injuries in Nepal, 2001-2013: Systematic Review and Secondary Data Analysis. BMJ Open, 6, e010757. https://doi.org/10.1136/bmjopen-2015-010757

Kayani, A., King, M. J., \& Fleiter, J. J. (2011). Fatalism and Road Safety in Developing Countries, with a Focus on Pakistan. Journal of the Australasian College of Road Safety, 22, 41-47.

Khare, N., Gupta, S. K., Varshney, A., \& Athavale, A. V. (2012). Epidemiological Study of Road Traffic Accident Cases Attending Tertiary Care Hospital, in Bhopal Madhya Pradesh. National Journal of Community Medicine, 3, 395-399.

King, J. (2018). PW 0959 Safety for Women Travelling by Road in Developing Countries: Preliminary Results from Cambodia and Bangladesh. Injury Prevention, 24, A104.1-A104.

Kumar, P. S., \& Srinivasan, K. (2013). To Study the Socio Demographic Profile of Road Traffic Accident Victims in District Hospital, Karimnagar. International Journal of Research and Development of Health, 1, 136-140.

Kyu, H. H., Pinho, C., Wagner, J. A., Brown, J. C., Bertozzi-Villa, A., Charlson, F. J., \& Fitzmaurice, C. (2016). Global and National Burden of Diseases and Injuries among Children and Adolescents between 1990 and 2013: Findings from the Global Burden of Disease 2013 Study. JAMA Pediatrics, 170, 267-287.

https://doi.org/10.1001/jamapediatrics.2015.4276

Labib, M. F., Rifat, A. S., Hossain, M. M., Das, A. K., \& Nawrine, F. (2019). Road Accident Analysis and Prediction of Accident Severity by Using Machine Learning in Bangladesh. In 2019 7th International Conference on Smart Computing \& Communications (ICSCC) (pp. 1-5). IEEE. https://doi.org/10.1109/ICSCC.2019.8843640

Latremouille, M. E., Thouez, J. P., Rannou, A., Bergeron, J., Bourbeau, R., \& Bussière, Y. (2004). Is Sex a Relevant Variable for the Study of Urban Pedestrian Behavior? Research-Transport-Security (RTS), Lavoisier, No. 84, 171-188. http://worldcat.org/issn/07618980

Lin, M. R., \& Kraus, J. F. (2009). A Review of Risk Factors and Patterns of Motorcycle Injuries. Accident Analysis \& Prevention, 41, 710-722. https://doi.org/10.1016/j.aap.2009.03.010

Lin, T., Li, N., Du, W., Song, X., \& Zheng, X. (2013). Road Traffic Disability in China: Prevalence and Socio-Demographic Disparities. Journal of Public Health, 35, 541-547. https://doi.org/10.1093/pubmed/fdt003

Mahmud, K. T., \& Hilton, D. (2020). Does Microcredit Really Matter for Healthcare Expenditure of the Poor Fish-Farmers? Perspective from Rural Bangladesh. Journal of Poverty, 24, 147-167. https://doi.org/10.1080/10875549.2019.1668901

Mahmud, K. T., Parvez, A., Alom, K., Bakshi, R. K., \& Khan, M. A. (2019). Impact of Monthly Repayment System on the Household Healthcare Expenditure of the Rural Women Borrowers: Evidence from Bangladesh. Journal of Poverty, 23, 365-383. https://doi.org/10.1080/10875549.2019.1577324

Mahmud, K. T., Parvez, A., Alom, K., Wahid, I. S., \& Hasan, M. K. (2017). Does Microcredit Really Bring Hope to the Female Borrowers in Bangladesh? Evidence from the Agribusiness Program of BRAC. Journal of Poverty, 21, 434-453.

https://doi.org/10.1080/10875549.2017.1348421

Mahmud, K. T., Parvez, A., Hilton, D., Kabir, G. S., \& Wahid, I. S. (2014). The Role of Training in Reducing Poverty: The Case of Agricultural Workers Receiving Micro- 
credit in Bangladesh. International Journal of Training and Development, 18, 282-290. https://doi.org/10.1111/ijtd.12039

Mahmud, S. S., Hoque, M. S., \& Qazi, A. S. (2009). Road Safety Problems in Bangladesh: Some Major Initiatives, Constraints and Requirements. Transport and Communications Bulletin for Asia and the Pacific, 79, 61-89.

Mahmud, S. S., Hoque, M. S., \& Shakur, Q. A. (2011). Road Safety Research in Bangladesh: Constraints and Requirements. In The 4th Annual Paper Meet (APM) and the 1st Civil Engineering Congress, Organized by Civil Engineering Division Institution of Engineers, Bangladesh (IEB), Session V: Transportation Engineering-II (pp. 22-24). https://www.iebconferences.info

Mahmud, S. S., Talukder, M. M. A., Ahmed, I., \& Raihan, M. A. (2013). Road Safety Initiatives in Bangladesh. Jurnal Teknologi, 65, 53-60. https://doi.org/10.11113/jt.v65.2146

Martin, A., Lagarde, E., \& Salmi, L. R. (2018). Burden of Road Traffic Injuries Related to Delays in Implementing Safety Belt Laws in Low- and Lower-Middle-Income Countries. Traffic Injury Prevention, 19, S1-S6.

https://doi.org/10.1080/15389588.2017.1344354

Mashreky, S. R., Rahman, A., Khan, T. F., Faruque, M., Svanström, L., \& Rahman, F. (2010). Hospital Burden of Road Traffic Injury: Major Concern in Primary and Secondary Level Hospitals in Bangladesh. Public Health, 124, 185-189.

https://doi.org/10.1016/j.puhe.2010.01.004

McKenna, F. P., Horswill, M. S., \& Alexander, J. L. (2006). Does Anticipation Training Affect Drivers' Risk Taking? Journal of Experimental Psychology: Applied, 12, 1-10. https://doi.org/10.1037/1076-898X.12.1.1

Mohamed, M., \& Bromfield, N. F. (2017). Attitudes, Driving Behavior, and Accident Involvement among Young Male Drivers in Saudi Arabia. Transportation Research Part F: Traffic Psychology and Behaviour, 47, 59-71. https://doi.org/10.1016/j.trf.2017.04.009

Nadesan-Reddy, N., \& Knight, S. (2013). The Effect of Traffic Calming on Pedestrian Injuries and Motor Vehicle Collisions in Two Areas of the eThekwini Municipality: A Before-and-After Study. South African Medical Journal, 103, 621-625.

Naghavi, M., Wang, H., Lozano, R., Davis, A., Liang, X., Zhou, M., \& Aziz, M. I. A. (2015). Global, Regional, and National Age-Sex Specific All-Cause and Cause-Specific Mortality for 240 Causes of Death, 1990-2013: A Systematic Analysis for the Global Burden of Disease Study 2013. The Lancet, 385, 117-171.

Najaf, P., Isaai, M. T., Lavasani, M., \& Thill, J. C. (2017). Evaluating Traffic Safety Policies for Developing Countries Based on Equity Considerations. Journal of Transportation Safety \& Security, 9, 178-203. https://doi.org/10.1080/19439962.2016.1230163

Osayomi, T. (2013). Regional Determinants of Road Traffic Accidents in Nigeria: Identifying Risk Areas in Need of Intervention. African Geographical Review, 32, 88-99. https://doi.org/10.1080/19376812.2012.750224

Pebalo, F. P., Kwikiriza, N., Kiyita, C., Mahaba, T., Muwanga, E., Tinka, A. A., \& Odongo-Aginya, E. I. (2012). Risk Factors for Road Traffic Accidents in Gulu Municipality, Uganda. East African Medical Journal, 89, 345-350.

Peden, M., Scurfield, R., Sleet, D., Mohan, D. H. A., \& Jarawan, E. (2018). World Report on Road Traffic Injury Prevention. World Health Organization.

Potoglou, D., Carlucci, F., Cirà, A., \& Restaino, M. (2018). Factors Associated with Urban Non-Fatal Road-Accident Severity. International Journal of Injury Control and Safety Promotion, 25, 303-310. https://doi.org/10.1080/17457300.2018.1431945 
Puvanachandra, P., Hoe, C., El-Sayed, H. F., Saad, R., Al-Gasseer, N., Bakr, M., \& Hyder, A. A. (2012). Road Traffic Injuries and Data Systems in Egypt: Addressing the Challenges. Traffic Injury Prevention, 13, 44-56.

https://doi.org/10.1080/15389588.2011.639417

Raina, P., Sohel, N., Oremus, M., Shannon, H., Mony, P., Kumar, R., \& Yusuf, R. (2016). Assessing Global Risk Factors for Non-Fatal Injuries from Road Traffic Accidents and Falls in Adults Aged 35 - 70 Years in 17 Countries: A Cross-Sectional Analysis of the Prospective Urban Rural Epidemiological (PURE) Study. Injury Prevention, 22, 92-98. https://doi.org/10.1136/injuryprev-2014-041476

Rasool, F. A. A., Alekri, F. A., Nabi, H. A., Naiser, M. J., Shamlooh, N. M., Alnashaba, S. A., \& Al Sayyad, A. S. (2015). Prevalence and Behavioral Risk Factors Associated with Road Traffic Accidents among Medical Students of Arabian Gulf University in Bahrain. International Journal of Medical Science and Public Health, 4, 933-939. https://doi.org/10.5455/ijmsph.2015.14022015189

Rosenbloom, T. (2009). Crossing at a Red Light: Behaviour of individuals and Groups. Transportation Research Part F: Traffic Psychology and Behaviour, 12, 389-394. https://doi.org/10.1016/j.trf.2009.05.002

Rosenbloom, T., Nemrodov, D., \& Barkan, H. (2004). For Heaven's Sake Follow the Rules: Pedestrians' Behavior in an Ultra-Orthodox and a Non-Orthodox City. Transportation Research Part F: Traffic Psychology and Behaviour, 7, 395-404. https://doi.org/10.1016/j.trf.2004.10.004

Rubayat, A. N. A. N. Y. A., \& Sultana, N. A. Y. E. E. M. (2013). Reasons behind the Road-Traffic Accident in Dhaka City: An Empirical Study. International Journal of Research in Humanities, Arts and Literature (IJRHAL), 1, 47-56.

Saeed, K. M. I., Rasooly, M. H., Safi, N., Alkozai, A., \& Ahadi, J. (2016). Epidemiologic Pattern of Road Traffic Injuries in Afghanistan, 2013. Journal of Pioneering Medical Sciences, 6, 16-21.

Salvarani, C. P., Colli, B. O., \& Carlotti Júnior, C. G. (2009). Impact of a Program for the Prevention of Traffic Accidents in a Southern Brazilian City: A Model for Implementation in a Developing Country. Surgical Neurology, 72, 6-13. https://doi.org/10.1016/j.surneu.2007.10.008

Sarkar, S., Tay, R., \& Hunt, J. D. (2011). Logistic Regression Model of Risk of Fatality in Vehicle-Pedestrian Crashes on National Highways in Bangladesh. Transportation Research Record, 2264, 128-137. https://doi.org/10.3141/2264-15

Seid, M., Azazh, A., Enquselassie, F., \& Yisma, E. (2015). Injury Characteristics and Outcome of Road Traffic Accident among Victims at Adult Emergency Department of Tikur Anbessa Specialized Hospital, Addis Ababa, Ethiopia: A Prospective Hospital-Based Study. BMC Emergency Medicine, 15, Article No. 10. https://doi.org/10.1186/s12873-015-0035-4

Sharma, B. R. (2008). Road Traffic Injuries: A Major Global Public Health Crisis. Public Health, 122, 1399-1406. https://doi.org/10.1016/j.puhe.2008.06.009

Shrestha, V. L., Bhatta, D. N., Shrestha, K. M., Krishna Bahadur, G. C., \& Paudel, S. (2017). Factors and Pattern of Injuries Associated with Road Traffic Accidents in Hilly District of Nepal. Journal of Biosciences and Medicines, 5, 88-100. https://doi.org/10.4236/jbm.2017.512010

Singh, D., Singh, S. P., Kumaran, M., \& Goel, S. (2016). Epidemiology of Road Traffic Accident Deaths in Children in Chandigarh Zone of North West India. Egyptian Journal of Forensic Sciences, 6, 255-260. https://doi.org/10.1016/j.ejfs.2015.01.008

Staton, C., Vissoci, J., Gong, E., Toomey, N., Wafula, R., Abdelgadir, J., \& Ratliff, C. D. 
(2016). Road Traffic Injury Prevention Initiatives: A Systematic Review and Metasummary of Effectiveness in Low- and Middle-Income Countries. PLOS ONE, 11, e0144971. https://doi.org/10.1371/journal.pone.0144971

Tay, R. (2008). Marginal Effect of Increasing Ageing Drivers on Injury Crashes. Accident Analysis \& Prevention, 40, 2065-2068. https://doi.org/10.1016/j.aap.2008.07.012

Touahmia, M. (2018). Identification of Risk Factors Influencing Road Traffic Accidents. Engineering, Technology \& Applied Science Research, 8, 2417-2421. https://doi.org/10.48084/etasr.1615

Tsala, S. A. Z., Ayissi, M. Z., Azeh, G., Noah, P. A., Ebanda, F. B., \& Ohandja, L. M. A. (2021). An In-Depth Analysis of the Causes of Road Accidents in Developing Countries: Case Study of Douala-Dschang Highway in Cameroon. Journal of Transportation Technologies, 11, 455-470. https://doi.org/10.4236/jtts.2021.113030

Tulu, G. S., Washington, S., Haque, M. M., \& King, M. J. (2017). Injury Severity of Pedestrians Involved in Road Traffic Crashes in Addis Ababa, Ethiopia. Journal of Transportation Safety \& Security, 9, 47-66. https://doi.org/10.1080/19439962.2016.1199622

Uddin, E., Hoque, N., \& Islam, R. (2017). Familial Factors Influencing Age-Heterogamy vs. Age-Homogamy in Marriage in Bangladesh: Implication for Social Policy Practice. Global Social Welfare, 4, 127-140. https://doi.org/10.1007/s40609-016-0064-2

Wangdi, C., Gurung, M. S., Duba, T., Wilkinson, E., Tun, Z. M., \& Tripathy, J. P. (2018). Burden, Pattern and Causes of Road Traffic Accidents in Bhutan, 2013-2014: A Police Record Review. International Journal of Injury Control and Safety Promotion, 25, 65-69. https://doi.org/10.1080/17457300.2017.1341930

Waseela, M., \& Laosee, O. (2015). Determinants of Road Traffic Injury among Adult Motorcyclists in Malé, Maldives. Asia Pacific Journal of Public Health, 27, 277-285. https://doi.org/10.1177/1010539514539544

Watts, G. R., \& Quimby, A. R. (1979). Design and Validation of a Driving Simulator. Report LR 907, Transport and Road Research Laboratory.

Whittam, K. P., Dwyer, W. O., Simpson, P. W., \& Leeming, F. C. (2006). Effectiveness of a Media Campaign to Reduce: Traffic Crashes Involving Young Drivers. Journal of Applied Social Psychology, 36, 614-628.

https://doi.org/10.1111/j.0021-9029.2006.00021.x

Wiebe, D. J., Ray, S., Maswabi, T., Kgathi, C., \& Branas, C. C. (2016). Economic Development and Road Traffic Fatalities in Two Neighbouring African Nations. African Journal of Emergency Medicine, 6, 80-86. https://doi.org/10.1016/j.afjem.2016.03.003

World Health Organization (2013). Global Status Report on Road Safety 2013: Supporting a Decade of Action: Summary (No. WHO. NMH.VIP 13.01). World Health Organization.

World Health Organization (2015). Global Status Report on Road Safety 2015. World Health Organization.

World Health Organization (2018a). Global Status Report on Road Safety 2018. https://www.who.int/violence_injury_prevention/road_safety_status/2018/en/

World Health Organization (2018b). Road Traffic Injuries: Key Facts. http://www.who.int/news-room/fact-sheets/detail/road-traffic-injuries

Yongchaitrakul, T., Juntakarn, C., \& Prasartritha, T. (2012). Socioeconomic Inequality and Road Traffic Accidents in Thailand: Comparing Cases Treated in Government Hospitals Inside and Outside of Bangkok. Southeast Asian Journal of Tropical Medicine and Public Health, 43, 785-794.

Zajac, S. S., \& Ivan, J. N. (2003). Factors Influencing Injury Severity of Motor Vehi- 
cle-Crossing Pedestrian Crashes in Rural Connecticut. Accident Analysis \& Prevention, 35, 369-379. https://doi.org/10.1016/S0001-4575(02)00013-1

Zhang, G., Yau, K. K., \& Chen, G. (2013). Risk Factors Associated with Traffic Violations and Accident Severity in China. Accident Analysis \& Prevention, 59, 18-25. https://doi.org/10.1016/j.aap.2013.05.004

Zimmerman, K., Jinadasa, D., Maegga, B., \& Guerrero, A. (2015). Road Traffic Injury on Rural Roads in Tanzania: Measuring the Effectiveness of a Road Safety Program. Traffic Injury Prevention, 16, 456-460. https://doi.org/10.1080/15389588.2014.973491

Zwerling, C., Peek-Asa, C., Whitten, P. S., Choi, S. W., Sprince, N. L., \& Jones, M. P. (2005). Fatal Motor Vehicle Crashes in Rural and Urban Areas: Decomposing Rates into Contributing Factors. Injury Prevention, 11, 24-28.

https://doi.org/10.1136/ip.2004.005959 